Ірина СНГАЛИЧЕВА, orcid.org/0000-0001-6824-9548 кандидат педагогічних наук, доцент, завідувач кафедри дошкільної освіти Черкаського наиіонального університету імені Богдана Хмельницького (Черкаси, Україна) ira2100@gmail.com

\title{
АНАЛІЗ ІНТЕРНЕТ-СЕРВІСІВ ДЛЯ УРІЗНОМАНІТНЕННЯ ОСВІТНЬОГО ПРОЦЕСУ В ЗАКЛАДАХ ВИЩОЇ ОСВІТИ
}

За умов стрімкого переходу освіти на онлайн-навчання видається неможливою організація якісного освітнього прочесу без використання сучасних засобів візуалізації навчального матеріалу. Ця проблема стала ключовою у визначені теми дослідження. 3 огляду на це у статті здійснено аналіз Інтернет-сервісів для урізноманітнення й унаочнення освітнього процесу у закладах вищої освіти.

На початку авторка аналізує ключові поняття, як-от: освітній прочес, візуалізація, Інтернет-сервіси. Визначення термінологї важливе для проведення дослідження та чіткості викладення матеріалу. У статті охарактеризовано основні можливості найбільш популярних і простих у використанні сервісів.

Для створення та редагування візуального навчального матеріалу, систематизачії інформації, проектної роботи авторка пропонує використовувати Draw.io-сервіс. Для подання інформації, щзо потребує відтворення хронологї подій, варто скористатися сервісом Timeline Knightlab, а для унаочнення викладу матеріалу мистецького або / та історичного спрямування у нагоді стане використання Apm-проекту Google.

Авторка наголошує, щз зручним інструментом для створення електронного супроводу уроку, заняття або дистаниійного курсу $\epsilon$ Blendspace-сервіс, а для створення інтерактивних завдань як для дітей, так $i$ для студентів на основі різноманітної кількості запропонованих шаблонів із різних предметів легким є LearningApps-сервіс.

На просторах Інтернету існує безліч сервісів для створення та зберігання інтерактивних звітів, презентаиій, фотоколажів, листівок, ігор тощь. Серед них иікавими та зручними є сервіси Sway, Symbaloo, VisualBee, Lоире. Увагу авторки як науковия привернула проста й безкоштовна платформа для сторення авторських електронних книг Ourboох. Корисним для збереження, організації та спільної роботи з різним контентом у визначеному віртуальному просторі є сервіс Padlet, завдяки якому можна розмішувати різноманітні види робіт (робити текстові нотатки, завантажувати файли, записувати та розмімувати відео- й аудіонотатки, додавати позначки, знаходити і додавати точки на мапі тощзо).

У статті акиент зроблено на перевірених $і$ зручних у користуванні Інтернет-сервісах, вказано на переваги та недоліки їх використання в освітньому процесі. На думку авторки, матеріали статті стануть у нагодi науковиям, викладачам та іншим учасникам освітнього прочесу.

Ключові слова: освітній прочес, візуалізаџія освітнього процесу, дистанційна освіта, онлайн-навчання, Інтернет-сервіси.

Iryna YENHALYCHEVA, orcid.org/0000-0001-6824-9548 Candidate of Pedagogical Sciences, Associate Professor, Head of the Department of Preschool Education Bohdan Khmelnytsky National University of Cherkasy (Cherkasy,Ukraine)ira2100@gmail.com

\section{ANALYSIS OF INTERNET SERVICES FOR DIVERSIFICATION OF THE EDUCATIONAL PROCESS IN HIGHER EDUCATION INSTITUTIONS}

Given the rapid transition of education to online learning, it seems impossible to organize a quality educational process without the use of modern means of visualization of educational material. This problem has become key in certain research topics. With this in mind, the article analyzes and systematizes the diversity of Internet services to diversify and illustrate the educational process in higher education institutions.

At the beginning of the study, the author analyzes key concepts, such as: the educational process, visualization, Internet services. The author is convinced that the definition of terminology is an important element in the research and the clarity of the presentation of the material. The article describes the main features of the most popular and easy to use services. 
Therefore, for the creation and editing of visual learning material, systematization of information, project work, the author proposes to use Draw.io-service. The Timeline Knightlab service should be used to present information that requires a history of events, and the use of the Google Art Project will be useful to illustrate the presentation of artistic and / or historical material.

The author emphasizes that Blendspace-service is a convenient tool for creating electronic support of a lesson, lesson or distance course, and LearningApps-service is easy for creating interactive tasks for both children and students based on a variety of templates from different subjects.

There are many services on the Internet for creating and storing interactive reports, presentations, photo collages, postcards, games and more. Among them are interesting and convenient services Sway, Symbaloo, VisualBee, Loupe. The author's attention, as a scientist, was attracted by a simple and free platform for creating author's e-books Ourboox. The Padlet service is useful for storing, organizing and collaborating with different content in a certain virtual space, thanks to which you can place various types of work (make text notes, upload files, record and place video and audio notes, add tags, find and add points to maps, etc.).

The article focuses on proven and easy-to-use Internet services, points out the advantages and disadvantages of their use in the educational process. According to the author, the materials of the article will be useful for scientists, teachers and other participants in the educational process.

Key words: educational process, visualization of the educational process, distance education, online learning, Internet services.

Постановка проблеми. Досягнення відповідності результатів освіти потребам всіх цільових груп, на які працює освітня галузь, визначає якість освіти загалом. Відомо, що сьогодні невід'ємною частиною освітнього процесу $\epsilon$ дистанційна освіта. За умов стрімкого переходу освіти на онлайн-навчання видається неможливою організація якісного освітнього процесу без використання сучасних засобів візуалізації навчального матеріалу. Особливо це актуальним стає під час «світової кризи», зумовленої пандемією.

Аналіз досліджень. Зрозуміло, що увагу науковців привертає використання різноманітних Інтернет-сервісів в освітньому процесі. Заявлена проблема фрагментарно висвітлювалася у наукових розвідках Марії Семаньків і Богдана Білусяка (Семаньків, Білусяк, 2018). На роль Інтернетсервісів у розвитку інформаційного середовища навчального закладу вказувала Маргарита Носкова (Носкова, 2017). Соломія Федушко, Софія Садова, Ірина Скірка здійснили аналіз ефективних Інтернет-сервісів для управління часом студентів вищих навчальних закладів (Федушко, Садова, Скірка, 2017). Віктор Немченко презентував відео з використанням універсальних Інтернет-ресурсів для унаочнення навчального матеріалу (Немченко, 2020) тощо.

Зрозуміло, що цей перелік наукових розвідок не вичерпується. Проте щодня з'являються нові, цікаві, популярні IT-технології, які сприяють візуалізації навчального матеріалу й відкривають можливості для оновлення змісту навчання та методів викладання.

Мета статті. 3 огляду на зазначене мета статті проаналізувати та систематизувати різноманітні Інтернет-сервіси для урізноманітнення й унаочнення освітнього процесу у закладах вищої освіти.
Виклад основного матеріалу. Досліджуючи це питання, вважаємо за необхідне з'ясувати зміст ключових понять. У ст. 47 Закону України «Про вищу освіту» чітко визначено, що «освітній процес - це інтелектуальна, творча діяльність у сфері вищої освіти та науки, яка провадиться у закладі вищої освіти (науковій установі) через систему науково-методичних і педагогічних заходів і спрямована на передачу, засвоєння, примноження і використання знань, умінь та інших компетентностей в осіб, котрі навчаються, а також на формування гармонійно розвиненої особистості» (Закон України, 2014).

Зрозуміло, що творчість краще розвивається завдяки візуальному оформленню поданої інформації. Науковцями термін «візуалізація» потлумачено як подання на пристрої відображення об'єктів у реальних (фотокартка) або умовних (діаграма) зорових образах (Б. О. Душков, О. В. Корольов, Б. А. Смірнов) (Душков, 2020); згортання розумового змісту в наочний образ, що служить опорою для адекватних розумових і практичних дій (А. О. Вербицький) (Вербицкий, 1991); спосіб фіксації та трансляції інформації, який не тільки доповнює, але й слугує альтернативою вербальнописьмової комунікації (О. О. Макарова) (Макарова, 2010) та ін.

Ми погоджуємося з думкою науковців і вважаємо, що візуалізація - це спосіб подання інформації у вигляді певного зображення (рисунка, діаграми, фотокарток, схем, таблиць, інтелект-карт, схем тощо) за допомогою технічних пристроїв із метою ефективного сприйняття інформації. Виходячи 3 цього, сьогодні очевидним та актуальним $\epsilon$ використання Інтернет-ресурсів. Інтернет-сервіси - це послуги, які надаються користувачам мережі Інтернет. 
Снгаличева I. Аналіз Інтернет-сервісів мля урізноманітнення освітнього процесу ...

Зібраний i проаналізований фактичний матеріал дозволяє стверджувати, що одним із доступних інструментів для роботи за умов дистанційного навчання $\epsilon$ сервіс Draw.io, який $є$ надзвичайно простим для створення та редагування візуального навчального матеріалу, систематизації інформації, проектної роботи. Draw.io-сервіс можна використовувати для створення опорних схем, інфографіки, інтелект-карт, графіків і діаграм та інших інтерактивних матеріалів у процесі вивчення будь-якого предмету (Немченко, 2020).

Для логічного викладу й успішного засвоєння матеріалу, що потребує відтворення хронології подій, доречним буде використання Timeline Knightlab. Це безкоштовний онлайн-сервіс, який не вимагає додаткової реєстрації в мережі. Достатньою умовою його використання $є$ наявність Google-акаунта. Перевагою цього сервісу $\epsilon$, по-перше, чітка та зрозуміла інструкція щодо алгоритму роботи, по-друге, те, що всі дані для створення стрічки часу вносяться шляхом роботи 3 Google-таблицею (Немченко, 2020).

Для унаочнення викладу матеріалу мистецького або / та історичного спрямування можна використовувати інтерактивні сервіси, серед яких варто вказати на Арт-проект Google. Використання Google Arts \& Culture дозволяє здійснювати віртуальні тури галереями музеїв, ознайоми- тися з фізичною та контекстуальною інформацією про художні роботи та створювати свої власні віртуальні колекції (Вікіпедія). Перевагою платформи $\epsilon$ різноманітність онлайн-екскурсій, інтерактивних галерей, доступ до зображень високої чіткості художніх робіт, які зберігаються у музеях, тощо. Варто зазначити, що, використовуючи інформацію, викладену на Google Arts \& Culture, варто дотримуватися авторського права (рис. 1).

Відомо, що нині вчителі / викладачі освітніх закладів мають значну добірку інформації, з якою можуть поділитися іншими учасниками освітнього процесу. Для зберігання інформації доречним буде використання сервіс-сховища Symbaloo, призначеного для забезпечення користувачів зручною панелю закладок, де можна розмістити будьякі посилання. За необхідності поділитися своєю добіркою посилань 3 іншими користувачами сторінку із закладками можна зробити публічною. Цкй ресурс дуже зручний у використанні у сфері освіти, адже як викладачі, так і студенти мають можливість представляти корисні посилання на навчальні програми, сайти.

Освітній процес у вищій школі базується на матеріалах, які є авторськими розробками самих викладачів. Для успішного здійснення професійних компетенцій, особливо під час дистанційного навчання, їм у нагоді стане платформа Ourboox.

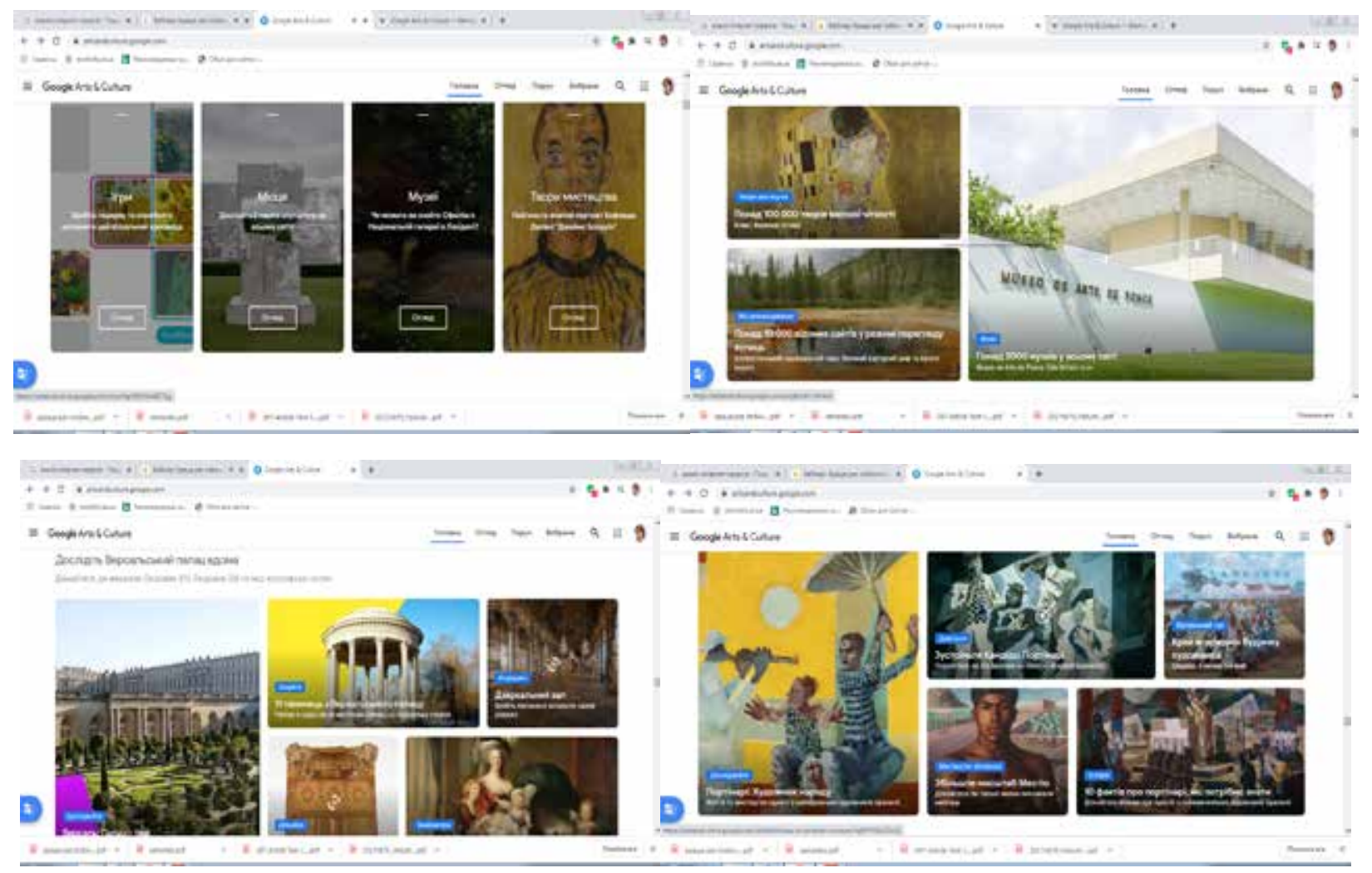

Рис. 1 


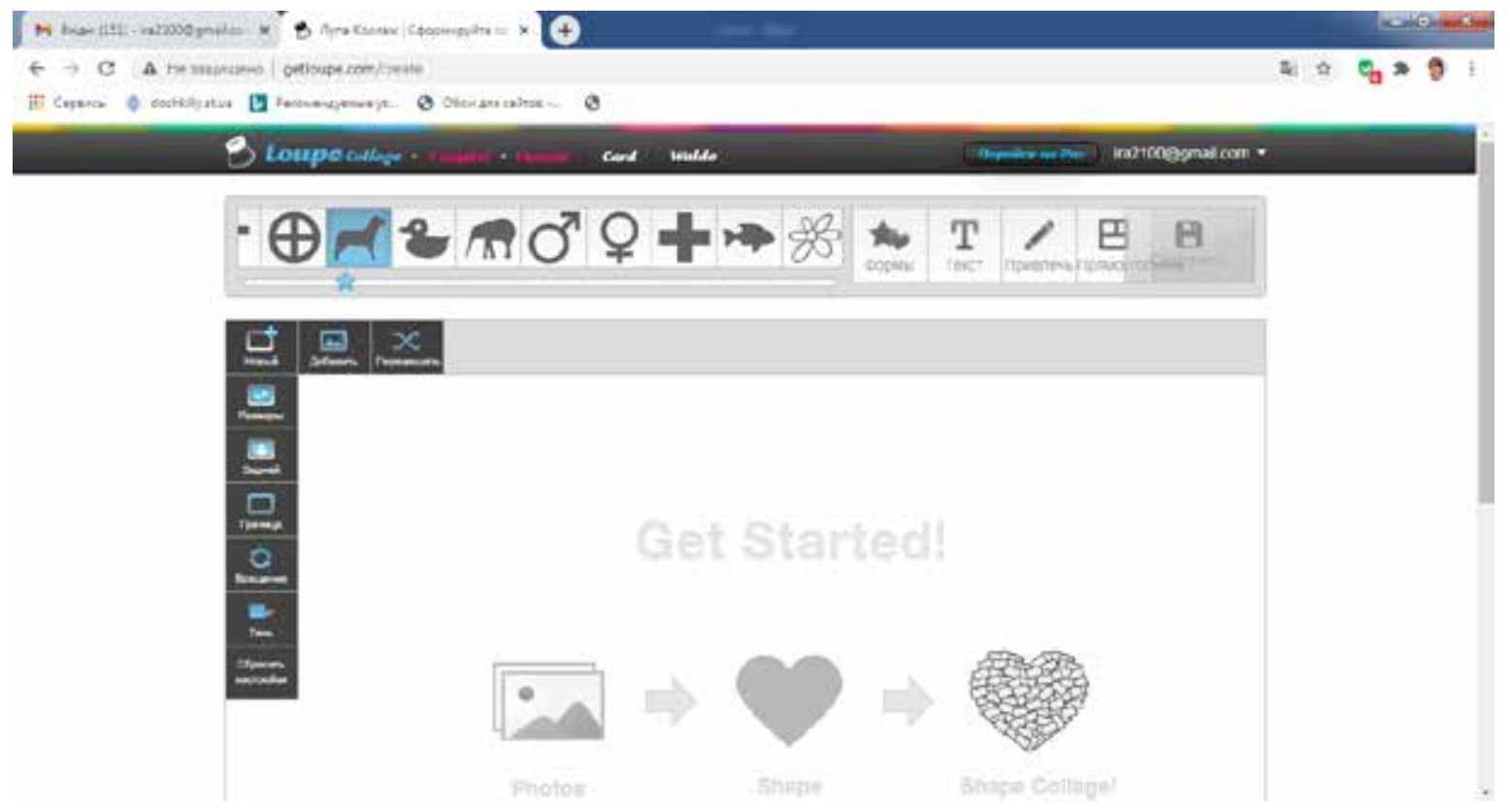

Pис. 2

Це проста і безкоштовна платформа для сторення авторських електронних книг (Семаньків, Білусяк, 2018; 98), що можуть включати відео, карти, ігри, головоломки. Перевагою платформи є те, що створивши книгу, автор має можливість поділитися нею в мережі, відстежувати кількість читачів i редагувати їі у будь-який час, навіть після того, як книгу було опубліковано. Однак недоліком, на наш погляд, є автоматичне виправлення окремих слів, написаних українською мовою.

Проаналізувавши численні Інтернет-сервіси для урізноманітнення освітнього процесу, зазначимо, що зручним інструментом для створення електронного супроводу уроку, заняття або дистанційного курсу $\epsilon$ Інтернет-сервіс Blendspace (Семаньків, Білусяк, 2018: 98), котрий дозволяє створювати тексти, відео, зображення, веб-сайти, Google-документи, вбудувати потрібні файли й онлайнові вправи, тестування чи опитувальник у вигляді вибору правильної відповіді. Перевагами Blendspace-сервісу $\epsilon$ : можливість зібрати «в одному місці» необхідні ресурси для заняття чи дистанційного курсу; організувати зворотний зв'язок з учасниками освітнього процесу; можливість писати коментарі та розміщувати посилання на виконані роботи; можливість викладачеві створити класну кімнату, занести туди всіх студентів i стежити за статистикою виконання завдань.

Одним із популярних сервісів в освітньому процесі є онлайн-дошка Padlet. Це зручний і легкий у роботі сервіс, призначений для збереження, організації та спільної роботи з різним контентом у визначеному віртуальному просторі. Padlet дає змогу розміщувати найрізноманітніші види робіт: робити текстові нотатки, завантажувати файли (word, pdf, jpg, png), розміщувати гіперпосилання (лінки), робити миттєві фото (Snap), записувати та розміщувати відео- й аудіонотатки, додавати позначки, зроблені вручну, знаходити та додавати точки на мапі, а за потреби - поширювати пряме покликання на іншу дошку Padlet. Використання сервісу стане у нагоді під час проведення «мозкового штурму», на етапі узагальнення та систематизації знань; як майданчик для розміщення навчальної інформації; для спільного або індивідуального виконання домашнього завдання; як місце для збирання ідей для проектів і їх обговорення.

Для покращення якості зображення презентацій пропонуємо використовувати сервіс VisualBee. Необхідною умовою використання сервісу, який є модулем для Microsoft PowerPoint, є установка та реєстрація як користувача. Встановлення сервісу є безкоштовним, що є великою перевагою для учасників освітнього процесу. Після відкриття програми PowerPoint VisualBee відкривається в окремому вікні та дозволяє вибрати новий стиль для презентації.

Нині, за умов дистанційної освіти, викладачі, працюючи 3 комп'ютерами, витрачають багато часу. Усвідомлюючи, що кожна година для викладачів є безцінною, пропонуємо скористатися програмою Sway, завдяки якій можна створювати інтерактивні звіти, презентації, заняття тощо та ділитися ними в мережі Інтернет. Перевагами сервісу є: економія часу на форматування створеної інформації завдяки вбудованому у програму конструктору; 
легка та швидка зміна оформлення презентації, якщо попередній варіант не вдався; можливість користування створеною презентацією іншими людьми за згодою автора, а за бажання - посилення контролю за вмістом, до якого надано доступ, шляхом зміни налаштування конфіденційності.

Цікавим для використання в освіті видається онлайн-сервіс Loupe, призначений для створення фотоколажів (Loupe Collage), листівок (Loupe Card), ігор (Loupe Waldo). Цей сервіс є безкоштовним, але для покращення якості використання пропонується оплата абонементу на місяць. Практика використання пропонованого сервісу дозволяе виділити переваги та недоліки його інструментів. Позитивними є: можливість реєстрації на платформі; широкий вибір шаблонів Loupe Collage; можливість формування фотографій і картинок за власним бажанням; можливість відстежити етапність створення листівок Loupe Card; збереження створених робіт і публікація їх у блозі, соціальних мережах, розсилка на e-mail; можливість працювати на інтерактивній дошці тощо. Серед недоліків можна вказати на: збій та (або) тривалість завантаження картинок і фотографій; складність роботи 3 інструментом Loupe Waldo, що полягає у незрозумілості створення онлайнових ігор (рис. 2).
Проаналізувавши сервіси для роботи зі студентами, найкращим вибором вважаємо LearningApps. Зручний інтерфейс сервісу дозволяє легко створити інтерактивні завдання як для дітей, так і для студентів на основі запропонованих шаблонів із різних предметів (Шперх). Зазначимо, що Конструктор LearningApps призначений для розробки та зберігання інтерактивних завдань iз різних предметів, дисциплін, за допомогою яких учасники освітнього процесу можуть перевірити та закріпити свої знання в ігровій формі, що сприяє формуванню їх пізнавального інтересу.

Отже, перелік пропонованих вище програм для урізноманітнення освітнього процесу не $\epsilon$ вичерпним. Кожен може знайти зручний і доступний сервіст для своєї роботи. Ми переконані, що матеріал статті стане у нагоді учасникам освітнього процесу.

Висновки. Можна впевнено стверджувати, що запорукою успішного викладу навчального матеріалу $є$ використання різноманітних Інтернет-сервісів, які нині є простими та доступними у використанні.

Перспективним видається більш детальний опис використання Інтернет-сервісів у процесі навчання конкретної освітньої галузі.

\section{СПИСОК ВИКОРИСТАНИХ ДЖЕРЕЛ}

1. Вербицкий А. А. Активное обучение в высшей школе: контекстный подход. Москва, 1991. 207 с.

2. Bсе про Symbaloo. URL: https://sites.google.com/site/vseprosymbaloo.

3. Душков Б. А. Энциклопедический словарь: Психология труда, управления, инженерная психология и эргономика. URL: http://vocabulary.ru/dictionary/896/word/vizualizacija. 2020.

4. Закон України «Про вищу освіту» від 01 липня 2014 р. № 1556-VII із змінами. 2014.

5. Макарова Е. А. Визуализация как интроекция смыслообразов в ментальное пространство личности : монография. Москва, 2010. 170 с.

6. Немченко В. Краще раз побачити: універсальні інтернет-ресурси для унаочнення навчального матеріалу. Освітній журнал «На Урок». URL: https://cutt.ly/Mg4k4Kf. 2020.

7. Носкова M. Роль інтернет-сервісів у розвитку інформаційного середовища навчального закладу. URL: https://cutt.ly/Ug4kCKh. 2017. C. 76-82.

8. Початок роботи з веб-програмою Sway. URL: https://cutt.ly/dg4kDTc.

9. Семаньків М., Білусяк Б. Використання Інтернет-сервісів в навчальному процесі. URL: http://itcm.comp-sc. if.ua2018semankiv.pdf. 2018. C. 97-100.

10. Сервic Loupe. URL: http://www.getloupe.com/create.

11. Федушко С. Аналіз ефективних інтернет-сервісів для управління часом студентів вищих навчальних закладів. URL: http://ena.lp.edu.ua/xmlui/handle/ntb/41994. 2017.

12. Google Arts \& Culture Вікіпедія. URL: https://uk.wikipedia.org/wiki/Google_Arts_\%26_Culture.

13. LearningApps.org - создание мультимедийных интерактивных упражнений. URL about.php.

14. Шперх A. LearningApps.org: більше ніж просто ігри. URL: https://cutt.ly/Gg4lxk4.

15. Padlet - віртуальна дошка для спільної роботи. URL: http://2webmkl.blogspot.com/p/httpsrupadletcom.html.

\section{REFERENCES}

1. Verbitskiy A. A. Aktivnoe obuchenie v vysshey shkole: kontekstnyy podkhod [Active Learning in Higher Education: A Contextual Approach]. Moskva, 1991. P. 207 [in Russian].

2. Vse pro Symbaloo. [All about Symbaloo]. URL: https://sites.google.com/site/vseprosymbaloo [in Ukrainian].

3. Dushkov B. A. Entsiklopedicheskiy slovar': Psikhologiya truda, upravleniya, inzhenernaya psikhologiya i ergonomika. [Encyclopedic Dictionary: Psychology of Labor, Management, Engineering Psychology and Ergonomics]. URL: http:// vocabulary. ru/dictionary/896/word/ vizualizacija. 2020 [in Russian]. 
4. Zakonu Ukrajiny “Pro vyshhu osvitu” vid 01.07.2014 № 1556-VII iz zminamy. [Law of Ukraine “On Higher Education” 01.07.2014 № 1556-VII]. 2014 [in Ukrainian].

5. Makarova E. A. Vizualizatsiya kak introektsiya smysloobrazov v mental'noe prostranstvo lichnosti. [Visualization as an introjection of meaning images into the mental space of a person: a monograph]. Moskva, 2010. P. 170 [in Russian].

6. Nemchenko V. Krashhe raz pobachyty: universaljni internet-resursy dlja unaochnennja navchaljnogho material [It is better to see once: universal Internet resources for visualization of educational material]. URL: https://cutt.ly/Mg4k4Kf.2020 [in Ukrainian].

7. Noskova M. Rolj internet-servisiv u rozvytku informacijnogho seredovyshha navchaljnogho zakladu [The role of Internet services in the development of the information environment of the educational institution]. https://cutt.ly/Ug4kCKh. 2017. pp. 76-82 [in Ukrainian].

8. Pochatok roboty z veb-proghramoju Sway. [Getting started with the Sway web application]. URL: https://cutt.ly/ dg4kDTc [in Ukrainian].

9. Semanjkiv M., Bilusjak B. Vykorystannja Internet-servisiv v navchaljnomu procesi [Use of Internet services in the educational process]. URL: httpitcm.comp-sc.if.ua2018semankiv.pdf. 2018. pp. 97-100 [in Ukrainian].

10. Servis Loupe. [Service Loupe] URL: http://www.getloupe.com/create [in Ukrainian].

11. Fedushko S. Analiz efektyvnykh internet-servisiv dlja upravlinnja chasom studentiv vyshhykh navchaljnykh zakladiv [Analysis of effective Internet services for time management of students of higher educational institutions]. URL: http://ena.lp.edu.ua/xmlui/handle/ntb/41994. 2017 [in Ukrainian].

12. Google Arts \& Culture/ URL: https://uk.wikipedia.org/wiki/Google_Arts_\%26_Culture [in Ukrainian].

13. LearningApps.org - sozdanie mul'timediynykh interaktivnykh uprazhneniy. [LearningApps.org - creation of multimedia interactive exercises]. URL: http://learningapps.org/about.php [in Russian].

14. Shperkh A. LearningApps.org - biljshe nizh prosto ighry [LearningApps.org - more than just games]. URL: https://cutt.ly/Gg4lxk4 [in Ukrainian].

15. Padlet - virtualjna doshka dlja spiljnoji roboty [Padlet - virtual board for collaboration]. URL: http://2webmkl.blogspot.com/p/httpsrupadletcom.html [in Ukrainian]. 